tomach. She had menstruated scantily at nine, but only trice since. Feet very cold, and bowels constipated. By the application of a galbanum plaster to the throst, milk diet, and exercise, cured.

Bright* mentions the case of a female brought into Guy's Hospital, suffering from stricture of several weeks' duration. The introduction of a probang brought on a fit of hysteria.

Stricture from Gout. A cise fell under my notice a short time back, where a person, while suffering from an attack of gouty spasm of the stomach, everything was rejected the moment it reached the lower part of the pharynx.

Mr. Watson (quoted by IIowship) speaks of a case occurring in a gouty gentleman.

Courant describes a case where it preceded the paroxysin of gout.

Stricture froy Scppiession of Cctayeods Eruptions. Manclerc, + a casc in a nervous fenale, where the suppression of an eruption on the biack of the hand, by an astringent application, was followerl ly vomiting and spasmodic constriction of the throat.

Aird mentions the casc of his son, aged 18, in whom the sudden disappcarance of a chronic cruption was followed by swelling and pain in the umbilical and hypochondriac regions, and spasm of the resophagus.

Stricture from Afrections of the Mind. An instance is recorded in one of the old writers, of a man who could not swallow a consecrated wafer. Another case is also mentioned, of a monk who never could swallow a particular kind of fluid, some of which liad once found its way into the trachea.

Boyer mentions an instance of a female, who, having once had a piece of chicken arrested in the throat, never after could swallow any without its inducing spasm.

I am acquainted with an individual who cannot take a very small new potato, from a surfeit in early life. The moment one is introlucel into the mouth, a sense of constriction is produced; and if he attempts to swallow it, it is rejected.

Percival relates an instance where swallowing a pea excited spasms of five or six (lays' duration in an elderly lady.

Duchateau ('lome 79 of Jour. (ién. de Méd.) has published the case of a nervous female, who fancied that she had swallowed a pin. She was at last cured by an enema, and then showing her a pin, telling her it had been discharged from the bowel.

Mondiere (Arch. Gén. de Méd. 1४33) cites the following cases:

A man, the subject of hypochondriasis, after being bitten by a dog, touk to his bed, and had difticulty in swallowing for fifteen days. But on Ferrier telling him that persons suffering from hydrophobia died on the eighth day, he got up and went about his usual occupations.

Barthelemi, the professor at $\Lambda$ lfort, was bitten by a little

dog. He believed that he was suffering from hydrophobia. For three days he was unable to swallow; the sight of water affecting him like electrical shocks.

Barbatini mentions an instance where a man, while out hunting, was bitten by his dog. The dog did not return home with him. Three days passed: the idea then took possession of him that he was hydrophobic. He had soon all the symptoms, even to occasional attacks of furor. On the ninth day the $\log$ returned, well and playful. From that moment he hecame quite well.

A man had been absent from heme for twenty years. On his return, he learnt that his brother had died of hydrophobia, from the bite of a dog which had also bitten himself. Ile was immediately seized with all the symptoms of the disease, and sank under it.

In flaymation of the U PPER part of the Spival Cord. Hoffuan mentions an instance where spasm of the cesophagus existed in a case of inflammation of the upper part of the cord.

Harringten Siquare, London, July lisis.

- liepurts of Medical Cases, vol. ii.

+ Jour. Gén. de Méd., tome xxii.

\section{TURPENTINE IN THE TREATMENT OF PURPURA.}

By WM. SMITH, Surgeon, Fellow of the Royal Medical and Chirurgical Society of London, etc.

In the Association Jodrsal for June 27th, is a review of Dr. Neligan's work "On Diseases of the Skin"; and some remarks on the treatment of purpura by oil of turpentine.

Having recently had under my care two serere cases of this disease, and having treated each of them differently, I trust a comparative view of the remedial effects of the medicines employed will not be uninteresting. I must premise that my attention was drawn to the use of oil of turpentine by Dr. Copland's recommendation of it in the article ont his disease in his Dictionary. The mode, however, in which I administered it, was advised by a gentleman of great practical experience in the treatment of disease, now retired from the profession, and who informed me that he had always found it successful in cases uncomplicated with organic disease.

The cases (which I purposely report very briefly), are as follows:-

F. $\mathbf{W}$, aged 6 , residing at Bolsover, Derbyshire, was attacked with large spots of purpura, principally on the lower extremities in the autumn of 1852 . Her mother employed domestic and other remedies till the spring of 1853, when, the child becoming much worse, she called me in.

The patient was a very fine though somewhat plethoric child, with ruddy sanguine complexion, and with all the external appearances of mide health. The locality in which she resides is one of the highest and driest in England, and distinguished generally by the longevity of its inhabitants. About six-serenths of the cases which fall under my care are, however, of the zymotic class. The drainage is bad, and many of the wells have been poisoned by the leakage of the cesspools. During the spring and summer of 1852, malignant scarlatina prevailed to in immense extent, and during this and last year furunculoid eruptions and erysipelas have been common and severe.

In the case now narrated, the child had for some time lived chictly on animal food, in fact, on the usual farm house diet-bacon. On my first examination of her, March 15 th, 1853, several very large ecchymoses were present on the legs, and one of the size of an egg on the forehead, the result of a slight blow. The smallest pressure produced them. There had been considerable bleeding from the nose on several occasions, and once from the bowels. There was oozing of blood from the gums. The urine was high coloured, and the alvine eracuations pale and generally constipated. I treated this case first with purgatives, and then with diluted sulphuric acid. She was also ordered to suck oranges, drink lemonade or very weak beer, and to eat rhubarb tarts.

The case did not progress with this treatment; the epistaxis was, indeed, somewhat diminished, but the other symptoms continued much the same.

Under these circumstances I gave the child citrate of iron combined with citric acid. This succeeded better, and after three months perseverance, the cutaneous discolorations ceased. The progress of cure was, however, extremely slow, and a relapse has since occurred, but the patient has again recovered under the use of the citrate of iron.

The second case occurred in a little girl, aged 4, generally strong and active, and residing in a spacious house situated near a tannery. This case was very acute. There was first remarked in her a disinclination to food, especially regetable; and extreme irritability of temper. The bowels were extremely constipated. These symptoms ushered in the attack. The lower extremities became weary and stiff towards evening, and three large elevated spots, varying from the size of a fourpenny piece to that of half-a-crown appeared upon them. These spots became rapidly purple and soft, and gave the impression to the touch of fluid blood under the skin. In the morning they became yellow, and gradually were absorbed, but others, larger and higher up 
the loge sucoeeded. Two formed of a very hrge sise in the hams, and the skin became so thin that I thought it would give way. The child, in threo days, becamo pallid and exsanguine, and her pulse very sharp and hemorrhagic. After using a mercurial purge, I at once resorted to the following mixture.

R Olei terebinth. 3 ss.

Olei ricini žj.

Mucilaginis,

Sacchari, àa, q. s.

Olei caryophyl. gtts. iv.

Aquæ dist. ad ऊ vij

Misce ut fiat mistura, cujus sumat cochlearia ij. vel iij. bis vel ter in die.

The effect of this mixture was most satisfactory. The purpuric spots rapidly disappcared, the bowels acted copiously and naturally, the appetite of the child became good, and the temper cheerful.

I certainly believe that in all passive hæmorrhages, turpentine will be found most valuable in its effects; and in this class of diseases we must generally place purpura.

Chesterfield, August 26th, 1953.

\section{GALLIC ACID IN THE TREATMENT OF PURPURA HAMORRHAGICA.}

$$
\text { By T. P. J. GIIANTH.AI, Esq. }
$$

Some years ago I lost one very dear to me from purpura hæmorrhagica: and my attention was thereby strongly directed to that disease, with the hope of discovering some more satisfactory mode of treatment.

The value of gallic acid in passive hæmorrhages induced me to give it a trial in purpura hæmorrhagica, and the results obtained were very gratifying. Moreorer, its safety, promptness, and pleasantness, are no inconsiderable recommendations of this remedy.

If the reader should not find any novelty in the application of gallic acid to this discase, the subjoined cases will at least confirm, as far as they go, the value of the treatment.

CASE I. Mr. E., a farmer and miller, aged 60 years, came under treatment on the 18th November 1852. Two days previously, he had noticed a soreness of the tongue, and perceived that the saliva was bloody. The symptoms of purpura were well marked. The gums were spongy, and they bled freely. The tongue and the buccal mucous membrane werc dotted with purple fungoid excrescences, some of which were as large as split peas, and from them blood cozed. The breath was offensive, and the appetite was impaired. The urine contained a considerable quantity of blood. Petechiæ were scattered over the thoracic and dorsal regions; and there was a large ecchymosis on one arm, and another on one of the thighs. The gallic acid was administered in five grain doses every three hours, and two compound rhubarb pills were given at bedtime. On the 20th, the purple excrescences had shrunken and ceased to bleed; the petechir and ecchymoses had faded; and the urine was free from blood. On the 30th, the improvement had been sustained. He was quite well again. He said that the first dose of medicine seemed to do him good. Only four scruples were taken.

CASE II. This was a more serious case, several days having elapsed from the first setting in of homorrhage from the nose before the patient came under my care. Master C., aged 16 years, a draper's apprentice, was seen by me on the 21st June 1853. He was greatly exhausted and blanched from epistaxis, hxmoptysis, melæna, hæmaturia, petechiæ, and ecchymoses. He was immodiately ordered to take gallic acid in doses of three grains every three hours, and subsequently in five grain doses every two hours. The pil. rhei comp. was given as an aperient. The treatment was followed by most marked benefit, and before a week had elapsed, all hæmorrhage had ceased. On the 5th July, a slight recurrence of epistaxis happened, oring to his haring too soon resumed sctive exercisa But the bleoding was quictly checked by a few dowes of the acid, and complete convalescence speedily followed.

CASE III. H. B., aged 12 years, son of an agricultural labourer, after three weeks illness from typhus, then prevalent in the village where he resided, was seized on the 16th August 1853, with hæmorrhage from the nose, gums, and bowels. The tongue was dotted with purple spots, and the back sprinkled with numerous small petechix. The treatment adopted was the same as in the former cases. On the 17th, hæmaturia was superadded to the other symptoms, which were very severe. On the 18th, the hæmorrhages began to abate. On the 20th, the spots on the tongue and the petechix had faded; the hæmorrhages had nearly stayed. On the 21 st, a severe return of epistaxis occurred, from picking his nose. This was followed by alarming prostration of strength. He was ordered to take the acid every hour, and to have his nose plugged. On the 22nd, all bleoding had ceased. On the 30th, I found that there had been steady and daily improvement since last report. On the 31st, he was convalescent.

This was a severe case, as the patient's strength had been so much reduced by a previous exhausting disease ; and, accordingly, it was necessary to push the acid to a considerable extent.

In all the cases the dietetic and general management were carefully attended to.

Burgh-le-Marsh, J.incolnshire, Sept. 1st, 1853.

\section{ON FEVER IN RURAL DISTRICTS.}

By W. VINER BEADLE, M.D.

Is recent numbers of the Association Jodrnal, I find reports of discussions at the Epidemiological Society, on different kinds of fevers. On a subject of such importance I venture to break the seal of silence, the "sigilla grata pudico", and to offer the following remarks on the Fevers of Rural Districts, as I have myself observed them.

My own impression is, that all the true fevers are closely connected with one another in origin and nature; that certain endemic even more than epidemic causes may produce these; but that, once brought into existence, they may under certain circumstances, only moderately favourable, be propagated; but that, these favouring circumstances being removed, they sink for want of their proper pabulum.

I, therefore, fully agree with the remarks of Dr. Southwood Smith, that "ferer is no doubt capable of extinction. The old fevers are now unknown; and were the earth cultivated like a garden, and the people all rational beings, it would soon cease." New modified forms, it is true, may arise of the same type, and yet bear no further comparison than does our present newt to the icthyosaurus of geologists.

On looking at the number of deaths by typhus in the Registrar-General's report for 1842 , I find it to be 16,201 , of which a large proportion occurred in country districts. It is to this latter class that I now more especially refer.

Amongst the circumstances which I recognise as the most favourable to the development of typhus fever, are-

1st. The nouveau séjour of Broussais, in places where the resident inhabitants are little affected.

2nd. (a) The want of drainage and ventilation; (b) human effluvium concentrated; (c) damp and consequently a cold and depressing neighbourhood and soil.

3rd. Though in a less degree, infection from those already affected, if also exposed to the same polluting influences.

Such is my impression of the origin of our fevers; and such causes must be efficiently removed ere fevers will vanish. I do not mean to speak dogmatically, since I am happy to say that my experience is comparatively limited; though even the cause of that limitation is not without a bearing on the subject. "Many years ago", remarked a gentleman to me, "fever always raged here towards the autumn; and many who were able felt great anxiety to escape at that time from the town." Now, however, since 